\title{
EMBODIMENT AT THE CROSSROADS BETWEEN COGNITION AND SEMIOSIS
}

\author{
Patrizia Violi ${ }^{1}$ \\ 1. Is there any such thing called cognitive \\ semiotics?
}

I have started this article with a provocative question, which may sound even more provocative in a special issue devoted to Cognitive Semiotics. However, if we look more closely at the general area of semiotic research often referred to as Cognitive Semiotics, we find so many different approaches and such a variety and diversity of conceptions and methodologies that this makes it very difficult to speak of a unitary discipline.

Cognitive Semiotics ought to emerge at the crossroads between Semiotics and Cognitive Science. However, the complex relationship between these two disciplines has followed a problematic, and in some sense paradoxical, path, since they seem at the same time too close and too distant from one another.

Viewed from a peircian perspective, the designation "cognitive semiotics" appears a tautological definition, since cognition and

1 Professor of Semiotics, Department of Communication, University of Bologna, Italy. 
semiosis relate to exactly the same phenomenon, and thus overlap completely.

On the other hand, the structuralist tradition in semiotics has always been pervaded by a well diffused mistrust of any form of psychologism : since anti-mentalism was the dominant position, this brought with it a widespread rebuttal of any kind of work on cognitive aspects of semiotic processes. The issue of whether or not such a position depends on a much too restrictive idea of what cognition can, or may be, is a different matter altogether, and one which I will not concern myself with in this present article.

Today, however, a concomitant shift in the two paradigms is allowing, and demanding, a reframing of this question, and opens up, in my opinion, some interesting common ground for further investigation. Such an investigation could, if successful, very well contribute to producing a more appropriate framework for a Cognitive Semiotics.

What I will argue in this paper is that such a framework can be developed only if the crucial issue of the body and its role, not only in cognition, but also in meaning processes in general is placed at the centre of focus for the new field. The shift towards an embodied approach to the issues mentioned above is already in the air, although, as I intend to claim, some further qualifications will be necessary in order to develop it fully.

In the last 15 years, within the particular sub-fields of Cognitive Science that go under the name of Cognitive Linguistics and Cognitive Semantics, the concept of embodiment has certainly become more and more popular, perhaps even too much so.

In the same period and in a parallel way, European semiotics also started investigating a related set of problems connected with the role of feelings, emotions, and sensory and perceptual elements -in a word : the embodied dimensions of meaning. Today, the "corporeal turn" seems to characterize many different disciplines, all concerned in one way or another with language, meaning and cognition, although such a turn may well have followed different trajectories and positions. Where in cognitive approaches the body is often considered in terms of its neuro-physiological dimensions, in the post structuralist semiotics what is at stake is not only the body with its sensory-motor devices, but also the emotions and feelings that animate it.

However important such differences may be, the need for a better understanding and confrontation between these two main 
traditions is generally recognized. Fontanille ${ }^{1}$ claims, for example, that a semiotics oriented toward the analysis of sensitivity and 'sensitive modes' cannot develop while ignoring the current state of cognitive research. Here he makes reference to the work of Varela, Thompson, Rosch ${ }^{2}$ and their concept of "enaction", which is an embodied action. In what follows I would like to investigate some of the basic tenets of embodied cognition, and look at some possible links with a more semiotically oriented approach. I would like to claim the following: i) there are today within the field of cognitive studies many very different notions of embodiment, only some of which are of real theoretical interest from a semiotic perspective. It is therefore crucial to distinguish among them in order to specify which type of conception of embodiment is most productive for cognitive semiotics; ii) embodiment is related in an important way to the problem of meaning processes, and it can help in a decisive way to reframe some of the most controversial questions in semantics. A context oriented, encyclopedic approach to meaning, which semiotics intrinsically offers, needs to take into account the role of the body; iii) the notion of 'body' is not a self-evident nor simple one, as is too often assumed in contemporary Cognitive Science; on the contrary the body is a constructed concept, and as such, cannot be reduced to purely neuro-physiological aspects nor to the brain. The kind of body that needs to be incorporated into Cognitive Semiotics is a phenomenological one, allowing us to open up for the central issue of subjectivity. Only given these basic conditions can embodiment come to represent a relevant contribution to cognitive semiotics.

But it is now time to have a closer look to what is exactly meant by "embodiment", and how it might constructively be related to a more specifically oriented semiotic approach.

\section{The various forms of embodiment}

In very general terms we could say that the main idea behind embodiment is that mind derives and takes shape from the fact that we

1 J. Fontanille, "Polisensorialità e autonomia della dimensione figurative", in P. BASSO, L. Corrain (eds.), Eloquio del senso. Dialoghi semiotici per Paolo Fabbri, Milano, Costa e Nolan, 1999.

2 F. Varela, E. Thompson, E. Rosch, The Embodied Mind, Cambridge, Mass., MIT Press, 1991. 
have a body that interacts with our environment. Such an assumption is generally seen as drastically opposed to classic representational cognitivism, which is based on functionalism and the computer-mind metaphor. According to functionalism, mind is independent from its material implementation, as the computer-mind metaphor suggests.

Implicitly connected to this position is a theory of concepts and semantic categories which is generally referred to as the "classic" theory, where it is claimed that it is possible to arrive at a precise definition of the semantic categories over and above, and independently from, their uses and contexts of application. In this perspective the body does not play an important role : it is essentially an output device, as often defined, merely executing commands generated in the mind through symbol manipulation.

In the embodied perspective, on the other hand, cognition is seen as depending in an fundamental way on the body and its perception and motor systems, as well as on bodily based experience and our interactions with the world.

Before going on to discuss these matters, we must immediately point out that there is no such thing as a unique theory of embodiment. On the contrary, the concept of embodiment is a very polysemic one, and different authors use it in quite different ways. Rather than referring to a single theory of embodiment, we ought to refer to different theories of embodiment, often highly divergent from one another, and sometimes having very little in common.

So let us now return to the issue of what might be considered the basic idea underlying the various approaches to embodiment. What exactly does it mean to say that the mind is embodied, and that it emerges and derives from the body? If we look more closely, we can see that there are many different readings of this same thesis, ranging from an extremely weak one to an extremely strong one, which is theoretically more interesting, but also more controversial. It will certainly prove useful to examine these various positions more closely, since only some of them will turn out to be of interest from a semiotic point of view.

A first, extremely weak interpretation would simply imply that all cognitive processes have a material basis. This is such a generic option that it would be difficult to disagree, but at same time it is so generic that it is not very meaningful. A more interesting assumption would be to say that cognitive processes cannot not have a material basis or, in other words, that cognition is directly connected to the 
various structures and biological processes that implement it. A somewhat similar version, still rather weak, implies that in order to understand mental processes one cannot ignore the way the nervous system and the brain work. In the last few decades, both neuroscience and neuropsychology have made such a position highly popular, and also widely accepted : today there are probably very few researchers in cognitive science who would disagree with it, with perhaps the exception of few more orthodox functionalists. From a semiotic point of view, however, this appears to be somehow a more background type of issue, since a semiotic analysis is not directly concerned with these more basic levels of description, but rather with the higher levels of sense organization.

A third interpretation, defined as "material" embodiment ${ }^{1}$, also takes into account -in addition to the idea that the mind depends on underlying neurobiological processes- the constraints imposed on cognition by real-time bodily actions performed by an agent in a real environment.

This is a quite popular position today in robotics, where research is focused on low-level cognitive tasks such as visual scanning or motion. Since it has to deal with the construction of robots able to perform real actions in a real environment, robotics must necessarily develop models of vision, perception and movement constrained by genuine perceptual-motor interactions with the environment.

Here embodiment means essentially taking into account the spatial-temporal constraints implicit in real bodies, but it does not imply any strong theoretical assumptions. Lakoff and Johnson ${ }^{2}$ distinguish here between embodiment as realization and embodiment as shaping.

Embodiment as shaping, often defined as full embodiment, or radical embodied cognition, is certainly the more popular position in contemporary cognitive semantics, and appears to be the one we should look at more closely from a semiotic point of view. According to this view, all concepts, even the most abstract ones such as those of mathematics ${ }^{3}$ are the result "of the way the brain and body are

1 R. NùnEZ, "Could the future taste purple ? Reclaiming mind, body and cognition", Journal of Counsciosenss Studies, 6, $\mathrm{n}^{\circ}$ 11-12, 1999, pp. 41-60.

2 G. LAKoff and M. Johnson, Philosophy in the Flesh, New York, Basic Books, 1999.

3 Cf. G. Lakoff and R. Nùnez, Where Mathematics Comes from: How the Embodied Mind Creates Mathemathics, New York, Basic Books, 2000. 
structured and the way they function in interpersonal relations and in the physical world"l.

Notice that in this quote from Lakoff and Johnson, brain and body are used as substantially interchangeable; this kind of overlapping is quite consistently found in many fields of research on embodiment. According to Nunez for example, embodiment explains concepts "in terms of the non-arbitrary bodily experiences sustained by the peculiarities of brains and bodies" .

This is a crucial question, since there is a potential ambiguity in considering body and brain as equivalents -an ambiguity that could produce potentially dangerous levels of confusion. Body and brain are not the same thing, as the phenomenological tradition, both of Husserl and of Merleau-Ponty, has taught us, a tradition to which most researchers today seem to refer. So this would seem to be a vital issue if we want to incorporate an embodied approach in a serious way into a cognitively oriented semiotics.

The body is something quite different from the brain, and if the latter can be seen as an immediate object for scientific study, the body certainly is not, in any direct and transparent way. Indeed, I would like to make the opposite claim, i.e. that the body is not at all a selfevident concept as it might appear at a first sight. I will come back to this point later.

For the moment I just want to make salient one specific ambiguity of this kind which underlies most work on embodiment. While material embodiment refers to the properties of the brain, and therefore the body in this model may be described as a body-brain, when we are speaking of embodied concepts or embodied cognition, a quite different meaning of "body" is at stake, much closer to the notion of "corporeal schema" than to that of the brain. Although embodied cognition might well have a neural plane of implementation, we have here two different levels of description, which do not coincide, and it would be helpful to keep them apart. Semiotics, with its phenomenological tradition, might very well play an important role in clarifying these issues and distinguishing between these two conceptual levels, of which only the second is, as I have already mentioned, of real semiotic concern.

I G. LAKOFF and M. JOHNSON, Philosophy in the Flesh, op. cit., p. 37.

2 R. NÜNEZ, op. cit., p. 56. 
Within the field of Cognitive Science, the picture is even more complicated, however, since the new paradigm is pursued within different disciplines and by means of different methodological approaches, which do not all necessarily share the assumptions of cognitive linguistics, not to mention those of semiotics.

To simplify, three main research domains relevant for our present discussion might be designated : connectionism (and neoconnectionism), robotics, and cognitive semantics, which is certainly the closest in spirit to cognitive semiotics. Each of these domains does not necessarily share the same notion of embodiment with the two others.

For example, many of the neo-connectionist models which use a dynamic modelling approach are not at all necessarily embodied, in the sense of having systematic, continuous relations with their actual perception and motor referents. What we have here is rather a conceptual interpretation which has little to do with empirical perceptive states, as Prinz and Barsalou have shown'. Connectionist nets do not guarantee embodiment, neither the radical embodiment of cognitive semantics, nor the weaker material embodiment.

Situated robotics, on the other hand, as I have already pointed out, has necessarily to take into account actual bodily constraints, since, in order to be fully operative the cognitive system underlying a robot must have an efficient interface with perception and action data : a simple abstract computing system would not be sufficient.

Maybe the main lesson we can derive from situated robotics is that to perform perception and action we cannot use only the cognitive system in itself, we need also to exploit the resources inherent in the body and the environment. As Clark ${ }^{2}$ claims, intelligence is not based exclusively on cognitive abilities -it evolves from the dynamic interaction between brain, body and world.

The concept of embodiment used in situated robotics is also different from the one used in the more theoretical fields of cognitive semantics and contemporary cognitive semiotics, which are crucially concerned with embodied experience. Both cognitive semantics and

1 J. PrinZ and L. Barsalou, "Steering a course for Embodied Representation", in E. Dietrich, A.B. Markman (eds.), Cognitive Dynamics: Conceptual and Representational Change in Humans and Machines, New Jersey, Lawrence Erlbaum, 2000.

2 A. Clark, Being There: Putting Brain, Body and World Together Again, Boston MA, MIT Press, 1997. 
semiotics see human experience as fundamentally bodily based : concepts and cognition emerge from our experience and are bodily grounded.

To conclude, there are probably more differences than similarities among researchers who explicitly refer to the notion of embodiment. For some, the "embodied" mind is still computational in a literal way, for others is not computational at all. Some refute completely the concept of representation, generally preferring dynamic systems, others, like Barsalou, refute dynamic systems and still use forms of representation. For some, embodiment exists only in authentically living systems (and not in simulations, not even connectionist ones), for others this is irrelevant ; finally for cognitive semantics and semiotics the crucial idea is that of phenomenological bodily experience.

What then do all these different approaches have in common? Well, probably the only real unifying aspect to be found is a critical one.

Embodiment theories are essentially a critical reaction to representational cognitivism, and in particular Fodor's functionalism. Here, there are two points of criticism : first, the non consideration of body-based 'material' aspects of cognition; second, the reduction of cognitive processes to purely syntactic symbolic manipulation.

From this point of view, theories of embodiment appear to be a natural development of cognitive semantics and cognitive linguistics of the seventies and eighties. Theoretical antecedents can be traced back to cognitive grammars, especially Space Grammar and Mental Space theory ${ }^{1}$; research on space and language ${ }^{2}$ and Force Dynamics, the system of forces that Talmy ${ }^{3}$ posits as the ground of the linguistic system of modality, which is essentially derived from embodied structuring.

I Cf. R. LANGaCKer, Foundations of Cognitive Grammar, Stanford, Stanford University Press, 1986 ; G. FAUCONnIER, Mental Spaces : Aspects of Meaning Construction in Natural Languages, Cambridge, MA, MIT Press, 1985.

2 See, among stothers L. TALMY, "How Language Structures Space", in H. PICK and L. ACREDOLo (eds.), Spatial Orientation : Theory, Research and Application, New York, Plenum Press, 1983.

3 L. Talmy, "Force Dynamics in Language and Thought", Papers from the Parasession Causatives and Agentivity, Chicago, Chicago Linguistic Society, 1985. 
A fundamental antecedent is also to be found in the critical review of the classical category theory that goes under the generic name of prototype theory ${ }^{1}$.

Since these seminal works first arrived, research in this field has continued to advance, reframing in a radical way some of its key concepts, beginning with that of representation.

\section{Body and situated meaning}

The representational issue is one of central concern for cognitive semiotics: at a first sight it might appear highly problematic to assume a strong anti-representational stance, as it is often the case within the field of research based on embodiment in the Anglo-American cognitive tradition. How could we possibly go without representations while the very notion of sign is nothing but a way to represent something by means of something else, according to Peirce? However, if we look more closely, the basic controversy appears to have been developed in a slightly different way. The antirepresentational controversy is more properly a controversy against a particular type of representation: symbolic representation, in the fodorian sense. Such a criticism, as we will see, is not at all contradictory to basic semiotic tenets, rather quite the opposite.

Rosch $^{2}$ for example claims there is a need to distinguish between two types of representation : the first is a device that mediates between mind and world, close to Peirce's idea of semiosis, connecting the external and internal worlds; the second is based on a notion used in classical cognitivism, where symbols are seen as syntactic symbols -formal operations within the closed system of a machine (or a mind, which is nothing but a machine).

One of the most important differences between these two models is the different ways they offer to look at context. Traditional cognitive science sees representations as stable, context-insensitive configurations that cannot be affected by contextual change. The socalled classical theory of categories was based on precisely such an

1 It is impossibile to provide even a very concise bibliography on this topic. For a critical reading of the theory, see $\mathrm{P}$. VIoLl, Meaning and Experience, Bloomington, Indiana University Press, 2001.

2 E. Rosch, "Reclaiming Concepts", Journal of Consciousness Studies, 6, n 11-12, 1999, pp. 61-77. 
assumption: a category might be a node, a network, a set of features, or a mental world, but was in any case always a static and immutable entity. In other words the basic idea was that one and the same invariant structure represents one particular concept in all possible contexts.

Now such a conception of the matter seems highly problematic : there is little doubt that natural cognitive systems exhibit a high degree of variety, and that our functioning in the world is much more flexible than any fixed structure could describe. Both our behaviours and our mental states adapt continuously to changing contexts, responding in a highly flexible way to environmental modifications. The traditional concept of representation thus turns out to be radically inadequate.

This is not something new in Semiotics: similar criticisms of the classical theory of representation have been developed within a semiotic perspective since the seventies. Umberto Eco in his $A$ Theory of Semiotics (1976)' has already pointed out the fundamental incapacity of any kind of invariant, dictionary-like structure to represent meaning, and successively, in 19842, he further elaborated the general notion of the encyclopedia as the only viable alternative to dictionary based models. From this point of view semiotic perspectives, at least those developed within a peircian interpretative framework, and those of cognitive semantics based on prototype theory are certainly highly compatible, as I have discussed elsewhere ${ }^{3}$.

At this point, however, my thesis is that developing the issue of embodiment can help us go even further and develop a more sophisticated approach to meaning and semiosis, and their relation to context, an approach that is theoretically more radical than that presupposed in Eco's models.

Concepts are indeed sensitive to contexts because we are embodied organisms and we interact with the environment. Embodiment and interaction are basic features of our semantic system, and more generally, of the ways in which we make sense of all our ongoing experience.

Taking embodiment seriously in describing meaning can help a semiotic approach to overcome some of the limitations that can still

1 Cfr. U. Eco, A Theory of Semiotics, Bloomington, Indiana University Press, 1976.

2 U. Eco, Semiotics and the Philosophy of Language, Bloomington, Indiana University Press, 1984.

3 P. VIOLI, Meaning and Experience, op. cit. 
be found in the encyclopedic model. Indeed the concept of encyclopedia, as elaborated by Eco, is a cultural construct that can account in terms of a regulative hypothesis for all possible cultural and social components of meaning, but has considerably less to say regarding the phenomenological side of our experience, although it does not in principle exclude it.

I believe that if something such as a cognitive semiotics is to be established as a field of study, it cannot avoid the incorporation of embodiment in its basic definition of cognition, and indeed the very taking of this incorporation of embodiment as its starting point.

Among the various embodied approaches we can already find some interesting suggestions in this particular direction.

Rosch, for example, emphasizes the role of situation and context in an embodied perspective. According to Rosch ${ }^{1}$ even when concepts appear to be universal and abstract, they always refer to specific and concrete situations. Real situations are events rich in information and should be the real object of study. Generally speaking, psychology tends to see contextual effects as negative elements that invalidate experimental work, but this perspective should be changed, and variations should become the main data for analysis.

Interestingly enough, the adoption of a strong contextualism of this kind parallels some recent positions in semiotics, where focus has been shifted from the system, and therefore from structural regularities, to process and text. The textual turn in semiotics implies making, and considering the text as a the real unit of analysis; this is compatible with Rosch's positions, where the single situation is considered to be the correct object of analysis. In both approaches we can find a common holistic component, which in some semiotic approaches appears to be extremely radicalized ${ }^{2}$.

Today, Rosch's broader assumptions regarding representations and the nature of concepts are quite different from her previous work on prototypes, and are embedded in a strongly holistic idea of the mind-world whole. Concepts are now seen as intrinsically nonrepresentational : they do not have the function of representing the world in the mind, nor do they mainly have an identifying function, as

1 E. RosCH, "Reclaiming Concepts", op. cit.

2 Cf. F. Rastier, M. Cavazza, A. Abeillé, Sémantique pour l'analyse. De la linguistique à l' informatique, Paris, Masson, 1994. 
is generally taken for granted in experimental research on naming tasks. Rather, concepts participate in situations.

"Concepts and categories do not represent the world in the mind, they are a participating part of the mind-world whole"1. Their participative nature derives from their being a natural mediation between mind and world, a mediation which is necessarily anchored into specific and locally defined situations. "Concepts are the natural bridge between mind and world to such an extent that they require us to change what we think of as mind and what we think of as world ; concepts occur only in actual situations in which they function as participating parts of the situation rather than either as representations or as mechanisms for identifying objects"2.

Even those who do not share such a radical position would agree not to conceive of representations primarily as structures that represent the external world, but rather as control structures for the regulation of interactions with the external world. This shift from mirror or encoding models to action-device models is quite common in current research on embodiment.

In robotics for example, Clark describes representations as control structures: "The idea here is that the brain should not be seen primarily as a locus of inner descriptions of external states of affairs ; rather, it should be seen as a locus of inner structures that act as operators upon the world via their role in determining actions"3.

Representations become here oriented toward action, while at the same time describing aspects of the world and prescribing possible actions, in a fine balance between pure control structures and passive representations of the external world.

It is worth noticing how much an approach of this kind to the issue of representation is close to the basic tenets of Peirce's pragmaticism. For the American philosopher too, concepts (and representations) are always correlated with actions: while concepts, seen as habits of mind, have a regulative function in relation to the internal world, stabilizing the process of unlimited semiosis, on the other hand when operative as beliefs, they also constitute the basis for behavioral and communicative habits, which are nothing but regularities in actions. In this way the very same semiotic structures

1 E. Rosch, op. cit, p. 72.

2 Ibid., p. 61.

3 A. ClaRk, Being There, op. cit., p. 47. 
regulate both the internal world of concepts and beliefs and the external world of actions, acting as a bridging system between the two.

A similar idea can be found in the model for memory proposed by Glenberg ${ }^{1}$, where memory does not primarily have a representative function "to store the past", but is rather an embodied device for facilitating interactions with the environment.

Such a perspective, largely shared among embodiment theorists, focuses on the role of the larger environment and its interactions with the organism, and on the relation between external and internal worlds. This explains a growing interest in Gibson ${ }^{2}$ and his concept of affordances. For Gibson too, representations and internal states that mediate the relationship with external world, are centred on action, or, to use Gibson's words, connected to affordances. Affordances are nothing more than possibilities for action and use offered by the local environment to a particular type of embodied agent, equipped with specific bodily features. In this way perception is always contextualized and constructed : the world is essentially perceived by some given organism endowed with its own intentions in some given context, and is seen as affording opportunities for goal directed actions. Perception is therefore always connected to action, and both perception and action are always connected to cognition.

This is a crucial point, because the action-perception-cognition link is perhaps one of the most important acquisitions of embodiment theories. Perception is never seen as a passive recording of information, but is immediately connected to action potentials. Therefore any kind of rigid distinction between perception and cognition disappears, and they become highly integrated and overlapping processes. Not surprisingly, such an approach is very interested in results of neuro-physiological studies that show a connection, even at neuronal level, between perception, action, thought and imagination. Recent research on mirror neurons have shown that in primates, and also in humans, the same neurons fire both when a given action (like grasping a cup of coffee) is effectively executed by some individual, and when it is observed while being executed by an other, and as well as when the subject merely thinks of

1 A. Glenberg, "What Memory is For", Behavioral and Brain Sciences, n²0, 1997 , pp. 1-55.

2 J.J. GiBSon, The Ecological Approach to Visual Perception, Boston, Houghton Mifflin, 1979. 
executing it. Interestingly enough, this does not happen just for any kind of movement, only for intentional actions, finalized to a goal (such as grasping a cup), and thus only for intentional interactions with the environment, or, to use Gibson's words : interactions connected to precise affordances.

The existence of underlying schemas common to perception, action, language and cognition probably represents one of the most challenging acquisitions of work on embodiment, and it is one that cognitive semiotics cannot ignore, since it implies a highest possible level of integration between all these systems. Perception, action, language cannot any more be considered as totally autonomous and independent modules, they must become functional specifications in a common unitary configuration.

This is also the ground of metaphorical concepts, so central in cognitive semantics, in that they represent linguistic and conceptual projections of bodily configurations of various kinds (perceptual, motor, spatial, and so on).

Metaphorical projections are always motivated; this is the second important lesson we can derive from embodiment studies. Together with the motivational aspect, this offers a radical challenge to the dominant view of language as a formal system, totally arbitrary and abstract. An important consequence of this work is a shift from the study of linguistic forms to the study of linguistic substances, a shift fully shared by contemporary cognitive semiotics. As Petitot suggests :

Il s'agit d'abord de rompre avec l'idéalisme sémiotique à l'œuvre dans les approches formalistes du sens qui auront dominé la grande période du structuralisme logicocombinatoire!.

Idealistic formalism has several important consequences : first of all it implies a totally disembodied approach to meaning : "Le sens perd tout rapport au monde naturel externe et au couplage perceptionaction qui fonde notre rapport écologique et éthologique à ce monde"2 Secondly, meaning is deprived of all self-organizing systemic principles and cannot but be purely logical and combinatory .

I J. PETITOT, "Les nervures du marbre. Remarques sur le "socle dur de l'être" chez Umberto Eco, in J. Petitot et P. FABbri, Au nom du sens. Autour de l'xure d'Umberto Eco, Paris, Grasset, 2000, p. 84.

2 Ibid, p. 85. 
A cognitive semiotics based on embodiment should pursue a double program that we could define at one and the same time as a deformalisation and a de-mentalisation of meaning and sense, reintroducing the study of substance as an essential part of its project.

\section{Which body for cognitive semiotics?}

The new field of embodiment has brought to light many interesting concepts and questions of central concern for a cognitive semiotics : firstly, there is a more realistic idea of the way human beings perceive and interact with their environment, and the way in which meaning emerges from these activities. Secondly, there is the interconnection between cognition, perception, and action ; the crucial relevance of situations and contexts, and a different and more articulated idea of the relationship between external and internal world. Finally, there is the central role of embodied structures in language and cognition, and the embodied nature of metaphorical mappings. All this points to a contextualist and pragmaticist conception of semiosis, in the peircian tradition, allowing an antiidealisitic and anti-formalistic shift in semiotics, such as the one advocated by Petitot. Embodiment allows and indeed requires a superceding of the purely logical and formal approach which had characterized semiotic structuralism in its initial period of development; meaning ceases to be a purely negative value, as it has been conceived in the saussurian tradition, but also acquires a living connection with our perceptional, phenomenological and emotional experience of the world. In this way world, experience, body and mind will all come to be seen as much more closely interconnected and strictly related to one another than before ${ }^{1}$.

These are all very important acquisitions, but however, there are still a few points which will need to be more carefully considered, and where I believe that semiotics will be able to contribute an important series of clarifications to the wider study of embodiment.

The first concept in need of a better understanding and clarification is, paradoxically, the very notion of "body". Body is often taken as a "natural" concept, and one which does not need any

1 On this point see P. COPPOCK, "Semiotics and the body: C.S.Peirce on the mindbody-world relation", Versus. Quaderni di studi semiotici. 
further elaboration. Apparently body is something easily accessible, objective, and physically defined. The body seems to be "there", possessing an immediate self-evidencing character which does not need to be explained.

But this is not the case. The body is not a self evident concept, but the result of the various discourses that construct it.

If the phenomenological experience of the body can appear an immediate one, the concept of "body" certainly does not. Rather, it appears to be seen in terms of the construals made of it within any given disciplinary perspective. In other words, the various meanings attributed to the notion of body are the sum of the various effects on sense of the different disciplines as they investigate and define it. The body as described by neurosciences is not the same body as the one described by psychoanalysis, or by experimental psychology, and so on. All these different "bodies" are not reducible to one another; on the contrary they produce a quite "heteroclitic" object, not very different from how language appeared to be when Saussure first started describing it. Many of the differences in the use of the very word "embodiment" that I have discussed so far depend on the different discourses that construct "body" in their respective ways as an object of research.

To conclude, I would like to point out some possible "zones of confusions" that appear to be particularly crucial in our current situation.

The first zone of confusion has already been mentioned, and concerns the interchangeable use that is sometimes made of the terms "body" and "brain". It is important to emphasize once again the complete lack of coincidence between these two levels : the body can certainly not be reduced to purely neural forms of activation. A "body-brain" of this kind would exclude the whole phenomenological dimension of experience, that live presence that Husserl called Leib, as opposed to the material Korper.

The second zone of confusion arises in relation to the distinction between body and corporeal schema. The confusion is more implicit than explicit, since corporeal schema are rarely mentioned, although the notion might represent a crucial concept for the discussion of embodied experience. 
The concept of corporeal schema was first used by psychiatrists and neurologists towards the end of the nineteenth century, and was then further elaborated by Paul Schilder in the mid nineteen-thirties ${ }^{1}$.

The corporeal schema is not only the general kinaesthetic experience we have of our body, but it is also the spatial dimension that is occupied by the body. According to Schilder it is neither a sensation nor a mental representation, but something intermediate between these two things. Merleau-Ponty ${ }^{2}$ refers to the notion of corporeal schema in order to define the 'corps propre' and its relationship with subjectivity. According to Merleau-Ponty the notion has a gestalt configuration and a dynamic character, implying an intentional dimension. The body is always endowed with a project in the world; it has its own goals deriving from its interactions with the environment.

The notion of corporeal schema seems crucial if we wish to investigate the embodied grounding of concepts, since at that level what is at stake is not the "body" as a material and natural object, but its schematic configuration, as has been well demonstrated in studies on spatialisation in language.

Finally, the third zone of confusion is regarding the relationship between body and subject. Confusion is probably not the right word here: "silence" would probably be a more appropriate one, since the question of subject and subjectivity is almost completely absent in North American work on embodiment. Why then use the word "confusion"? Well, this is because in several cases we can quite easily find implicit reference to something that we more appropriately would have referred to as subjectivity, but which is not always recognized as such.

Let us take as an example the very interesting article by Mac Whinney ${ }^{3}$, where the author analyses some of the different forms in which language emerges from embodiment. According to Mac Whinney "language comprehension and production are embodied processes whose goal is the creation and extraction of embodied

1 P. SCHILDER, The Image and Appearance of the Human Body, New York, International Universities Press, 1935.

2 M. Merleau-PONTY, Phénoménologie de la perception, Paris, Gallimard, 1945.

3 B. MAC WHINNEY, "The Emergence of Language from Embodiment", in B. MAC WHINNEY (ed.), The Emergence of Language, New Jersey, Lawrence Erlbaum, 1999. 
meanings (...) We can refer to these processes of active embodiment as the perspective-taken system"l.

The embodied perspectival systems operating in language are related to four levels : 1) affordances, where language and cognition are related to individual objects and actions through affordances ; 2) spatio-temporal reference frames, which refer to "the set of competing spatio-temporal reference frames"2 ; 3) causal action chains, most centrally involved in the emergence of grammar and the different perspectives of nominative-accusative language or ergative-absolutive language ; 4) social roles, where the perspectival system allows us "to adopt the social and cognitive perspectives of other human beings" 3 .

What is of interest here is that all of these systems are not equivalent in their relations to the issues of embodiment and subjectivity.

If the first level of affordances is certainly linked to the body and its grounding in the linguistic perspectival system, since all the properties we can think of in relation to an object are affordances grounded in the perspective of our own body, the same does not hold for the other three levels, where it is not so much the body that plays a role, but the point of view of the subject as represented in language. Consider the spatio-temporal reference frames. Mac Whinney explicitly mentions three alternative frames, an object-centred, a speaker-centred, and an environment-centred frame. These frames do not depend on the body, but on the way the position or perspective of the subject is framed within discourse. The same is true for the other two systems: both the perspective a given grammatical construction imposes on the action, and the perspective connected to interpersonal and social frames, refer to subjectivity more than to embodiment. What we have in these cases are traces left at sentence level by the process of enunciation. The notion of perspective can be framed in the wider issue of linguistic subjectivity, which, in European postsaussurian linguistics, has most convincingly been elaborated in the Theory of Enunciation ${ }^{4}$. Such a theory unifies in one and the same

Ibid., p. 214.

Ibid., p. 215.

3 Ibid., p. 216.

4 E. Benveniste, Problèmes de linguistique générale I, Paris, Gallimard, 1966 (tr. it. Problemi di linguistica generale, Milano, il Saggiatore, 1971); IDEM, Problèmes de linguistique générale II, Paris, Gallimard, 1974 (tr. it. Problemi di linguistica generale, Milano, il Saggiatore, 1985). 
framework a family of heavily interconnected issues, ranging from pronominal, temporal and spatial reference systems, to focalization, perspective, point of view, and so on.

So obviously the question is not whether or not we use enunciation theory as formulated in post-saussurian linguistics, but the possible overlappings that may be found between two different issues, both of which are extremely important, but which are not necessarily connected with one another. Perspectival systems depend on the presence in every sentence of an uncancellable point of view which is the trace of the enunciation process, and this is something quite different to embodiment, which is the existence, in both meaning and in language, of motivated configurations, all of which depend on embodied experience.

Given the extent to which these two issues are not the same, the theory of enunciation removes the issue of embodiment altogether, leaving only reference to a transcendental subject, completely deprived of any form of bodily qualification, gender difference or any other dimension which might be linked to individual subjects!.

Here we have a deeply paradoxical chiasmus : on the one hand there is a theory of embodiment without the subject, on the other a theory of the subject without a body. To finally achieve a bringing together of body and subject might well be the most challenging goal of all for a cognitive semiotics to be.

1 Cf. P. Viol, L'infinito singolare. Considerazioni sulla differenza sessuale nel linguaggio, Verona, Essedue, 1986. 